\title{
El exilio con Eduardo Nicol
}

\author{
Antolín SÁnchez Cuervo \\ Instituto de Filosofía - CSIC
}

RESUMEN. En 2007 se cumple el centenario Eduardo Nicol, uno de los filósofos más relevantes del exilio español de 1939, cuya obra no ha recibido aún, sin embargo, la atención que merece. A diferencia de otros pensadores emblemáticos de dicho exilio como José Gaos, Nicol se desmarcó de la filosofía «personalista» de Ortega, apostando más bien por la universalidad y objetividad del logos. Una de sus contribuciones originales a la misma fue su planteamiento de una ética dialógica, inspirada en la condición radicalmente expresiva del hombre y en el sentido comunitario de su existencia, frente a los reduccionismos del cientismo instrumental contemporáneo.

Palabras clave: Nicol, ética, exilio, filosofía española.

La creciente memoria del último gran exilio de la filosofía española apenas ha reparado aún en la obra de una sus principales voces, ya centenaria en el presente 2007, como Eduardo Nicol (1907-1991). Se trata de una obra desarrollada casi en su totalidad en el mismo México acogedor de dicho exilio, al que Nicol había llegado en 1939 en el célebre barco $\mathrm{Si}$ naia, tras cruzar la frontera hispano-francesa con el resto de tropa del Estado Mayor republicano, rendir armas al ejército francés y pasar un tiempo en el no menos célebre campo de concentración de Argelês-sur-mer. A lo largo de libros como La idea del hombre (México, Stylo, 1946), La vocación humana (El
AbStRact. In 2007 is completed the centennial Eduardo Nicol, one of the most excellent philosophers in the Spanish exile of 1939 , whose work has not still received, however, the attention that deserves. Contrary to other excellent thinkers of this exile like José Gaos, Nicol distanced from the «personalist» philosophy of Ortega, to outline rather for the universality and objectivity of the lógos. One of their original taxes to this was their position of a communicative ethics, inspired by the radically expressive condition of man and the community sense of their existence, in front of the constrictions of the contemporary instrumental «scientism».

Key words: Nicol, ethics, exile, Spanish philosophy.

Colegio de México, 1953), Metafísica de la expresión (FCE, 1957), El problema de la filosofía hispánica (Tecnos, 1961), Los principios de la ciencia (FCE, 1965), El porvenir de la filosofía (FCE, 1972), La reforma de la filosofía (FCE, 1980) y Crítica de la razón simbólica (FCE, 1982), entre otros, planteó Nicol toda una reforma de la razón filosófica, sensible a preocupaciones medulares de nuestro tiempo. Entre otras, la metafísica, cuya crisis contemporánea asumió y a la que respondió con un original planteamiento fenomenológico-dialéctico; la ética, a la que imprimió un sentido dialógico y comunicativo a partir de conceptos como los de acción y alteridad, a contrapelo de 
visiones individualistas y contractualistas de la política; los límites de ciencia, cuyos prejuicios epistemológicos desactivó y cuyos derroteros instrumentales actuales sometió a crítica; o el hispanismo, cuyas tendencias al «ensayismo» y al ensimismamiento sometió asimismo a una crítica severa aunque constructiva.

Quizá algunas disonancias notorias de este pensamiento respecto de otro tan poderoso e influyente, igualmente madurado en pleno exilio mexicano como el de José Gaos, así como de un bagaje filosófico tan significado en dicho exilio como el orteguiano, pudiera explicar su «olvido» hasta nuestros días ${ }^{1}$. No en vano mantuvieron ambos filósofos una jugosa polémica $^{2}$ que traslució dos maneras bien diferentes de pensar y en la que ahora no nos detendremos, aunque sí sea oportuno contrastar algunas de estas diferencias. Quizá una de las pudieran revestir una mayor actualidad fuera aquélla en torno a los límites y las posibilidades de un pensar en español. A la sólida y feliz reivindicación gaosiana de un pensamiento de lengua española digno en sí mismo, en su doble y singular condición «estética»y "político-pedagógica», aun cuando éstas no se ajustan - e incluso por eso mismo - a las supuestas condiciones teóricas - en definitiva arbitrarias- del saber filosófico en cuanto tal - orden sistemático, rigor científico, lenguaje abstracto..._-3, contrapuso Nicol una visión más adusta de la cuestión. Se desmarcó del mismo «ensayismo» rehabilitado por Gaos para reclamar más bien ese compromiso con la universalidad, esa aspiración al rigor sistemático y «científico» - en el amplio sentido del término, pues Nicol fue también muy crítico hacia el cientismo - y ese compromiso ético pendientes de asumir en el pensamiento en lengua española, especialmente desde el noventayochismo. Nicol no fue un pensador sencillamente eurocentrista $\mathrm{y}$ buena muestra de ello fue su volumen $E l$ problema de la filosofía hispánica, en el que asume y reconoce la idiosincrasia de esta última, tal y como se ha desenvuelto en las dos orillas. Pero sí apostó - a diferencia de Gaos - por una concepción logocéntrica del pensar como marco de comprensión crítico y fundamental de la cuestión.

Para Nicol esto significa, en primer lugar, un compromiso con la universalidad, entendida no como una abstracción conceptual o una idea reductora, sino como integración práctica de lo particular en la comunidad problemática de lo universal y proyecto ilimitado de convivencia. «Hay que ser más y preguntarse menos por lo que uno sea» - afirmaría a contrapelo del sentido intimista y personalista de reflexiones emblemáticas de la filosofía española como la del «quijotismo»—, lo cual pasa por la apertura de «un camino propio en la maraña de las doctrinas vivas y universales», mucho más - añadirá en clara referencia a Ortega- que por «la continuación de esa filosofía de la propia circunstancia, que es un asunto doméstico y no universal» ${ }^{4}$. En segundo lugar, rigor científico o compromiso con la «episteme» en un sentido asimismo distante de reduccionismos tanto metafísico-idealistas como pragmático-instrumentales, en respuesta a la condición netamente «ideológica» que a su juicio ha lastrado tan a menudo al pensamiento en lengua española $-\mathrm{y}$ de la que no dejarían de participar las meditaciones sobre el propio ser- ${ }^{5}$. Y en tercer lugar - y por citar sólo tres rasgos fundamentales - una concepción abiertamente comunitaria de la ética, pendiente aún de realizar, en estos términos, en un medio filosófico tan propenso al personalismo y a la evasión esteticista como el hispánico. Para Nicol, el hombre se juega su «ethos» o su lugar en el mundo en la medida en que da razones de esa misma realidad en la que vive y en la que se halla inmerso, algo que bien pudiera recordar al método 
orteguiano del «naufragio». Sólo que se trata siempre de un naufragio en común. Para Nicol, la condición responsable no es un asunto individual, de la misma manera que dar razones de la realidad significa, sobre todo, responder a la alteridad interpeladora de la comunidad. No es entonces «mi vida» — según la célebre expresión de Ortega - sino la vida en común el eje vertebrador del «ethos». Al igual que Ortega, Nicol fue bien consciente de la necesidad de una reforma de la razón, pero su planteamiento de la misma discurrió por unos derroteros bien distintos y distantes de los orteguianos. Y no porque diera la espalda a la vida como hecho radical, sino por el sentido de dicha radicalidad, personalista, estetizante e incluso tendente al solipsismo en un caso, dialógica y comunicativa en el otro.

Pero la reflexión de Nicol en torno al «ethos» del hombre contemporáneo desbordó los límites de toda disputa sobre las condiciones de posibilidad de la filosofía hispánica para articular una propuesta singular y de no poca actualidad. Su apelación a la comunidad no obedeció a contractualismos al uso — que más bien rechazó-, sino al rescate de la condición expresiva del lógos, olvidada por la metafísica occidental desde sus formulaciones platónicas dando lugar a no pocos seudoproblemas - entre otros el solipsismo, precisamente, además de innumerables dualismos- De acuerdo con su metafísica de la expresión, doblemente inspirada en una singular y complementaria asunción de los métodos fenomenológico y dialéctico ${ }^{6}$, la evidencia apodíctica del ser quedaría liberada de su tradicional condición tormentosa y abismal, si es que no incognoscible o inaccesible, haciéndose presente en la misma apariencia contingente de los fenómenos; presencia evidente cuya legibilidad reside precisamente en el lógos, entendido no como especulación, ni siquiera como discurso, sino como ex- presión o palabra, dialógica por definición. El hombre «no puede manifestarse a sí mismo sin manifestar el Ser, y esta manifestación del Ser sólo puede efectuarse en la comunicación dialógica» ${ }^{7}$. Dicho de una manera más sencilla y elocuente, «entender es entenderse con palabras» ${ }^{8}$ : es por tanto en la comunidad lingüística en donde el ser se hace presente, despejándose así el camino hacia una ética dialógica que busca un lugar propio entre los giros lingüísticos del pragmatismo e incluso la razón comunicativa por una parte, de la fenomenología heideggeriana y sus derivaciones hermenéuticas por otro. Frente a los artificios y las abstracciones atomizadoras de lo primero - y sus correlaciones contractualistas, basadas en la ficción de la soberanía individual—, apeló Nicol - quizá con un optimismo excesivo-a la evidencia compartida lógos como fuente primordial de verdad y de consenso práctico. Frente a la «hipostatización» del lenguaje a la manera de una instancia ontológica accesible sólo a poetas y pensadores propia de lo segundo, subrayó el carácter netamente mundano del mismo. «El hombre es el ser que habla del Ser» ${ }^{9}$, pero no para confinar dicho hablar en una trama de ocultaciones y desvelamientos ontológicos exclusiva del lenguaje poético-filosófico, o de horizontes primordialmente significados en la experiencia estética, sino para restituir su ilimitada proyección democrática. En la comunidad, «podemos apoyarnos para restablecer, junto con el carácter ético de la verdad, su carácter dialógico ${ }^{10}(\ldots)$ Hablar es responder» ${ }^{11}$.

Precisamente el deterioro de la palabra, la irracionalidad del verbo y el empobrecimiento del diálogo son claros indicios, para Nicol, de la crisis radical por la que atraviesa el hombre contemporáneo, como resultado de un pragmatismo extremo y una tecnificación de la cultura sin precedentes. A lo largo de dos libros fundamentales como El porvenir de la fi- 
losofía y La reforma de la filosofía, diagnosticó Nicol el actual dominio de la razón instrumental en todos los ámbitos de la vida. El «predominio totalitario de la utilidad» ${ }^{12}$, de una «razón de fuerza mayor» — como dirá a menudo- , de una razón puramente funcional que ha dejado de dar razones acerca del mundo para explotarlo técnicamente, o de una razón que sencillamente no atiende a razones, comprometerá entonces la existencia del lógos y en consecuencia del «ethos». El constreñimiento de la libertad bajo la necesidad y de la historia bajo la naturaleza; la devaluación de la universalidad en uniformidad tecnificada y de los vínculos comunitarios en vínculos de especie; la sustitución del diálogo por el discurso beligerante y de la búsqueda de la verdad por la lucha por la subsistencia - esto es, de la ciencia por la tecnología-; la creciente irracionalidad de la política y la progresiva instauración de una cultura de la violencia; o la deshumanización de la economía y la desigual distribución de recursos, son algunos de los caracteres de esta racionalidad forzada $-\mathrm{y}$ en definitiva contradictoria por su misma irracionalidad-. En definitiva, la política «em- plea la palabra como arma de guerra en tiempo de paz» ${ }^{13}$, «todos los hombres son en la actualidad heridos de guerra» ${ }^{14}$, y el ideal de una comunidad universal ha sido reemplazado por un estado de «guerra global» ${ }^{15}$. Nicol atinó con un diagnóstico — nada optimista esta veza la altura de tiempos particularmente violentos, aunque no exento, si bien, de una cierta ambigüedad que él mismo no oculta cuando señala a «un enemigo sin rostro» ${ }^{16}$, que parece actuar con una doble lógica. Por una parte, la que se hila con causas de orden más bien natural como el agotamiento de los recursos del planeta o la superpoblación. Por otra, la misma tendencia a la barbarie paradójicamente inscrita en el desarrollo de una civilización occidental que tal vez «haya tenido que desprenderse de su propia raíz para hacerse dominante» y que «se hizo indiferente respecto de su humanidad» ${ }^{17}$. En cualquier caso, Nicol fue uno de los filósofos en lengua española de las últimas décadas que más y mejor detectaron la irracionalidad de muchas razones vigentes en la actualidad. Estuvo por ello a la altura de nuestros tiempos oscuros.

\section{NOTAS}

\footnotetext{
1 En esta orilla al menos y con las debidas excepciones. Cf. el volumen colectivo Eduard Nicol: semblanza d'un filosof. Edició a cura d'Angel Castiñeira. Barcelona, Acta, 1991; José Luis Abellán: El exilio filosófico en América. Los transterrados de 1939. México, FCE, 1998, pp. 65-99 (versión actualizada y aumentada de Filosofía española en América (19361966). Madrid, 1967, que ya incluía un capítulo dedicado a Nicol); el monográfico Eduardo Nicol. La filosofía como razón simbólica editado por Anthropos. en 1998 (Extra 3). En el caso de México, cf. Juliana González: La metafísica dialéctica de Eduardo Nicol. México, UNAM, 1981; Luz María Álvarez Argüelles, Vladímir Saavedra Martínez, Claudia Márquez Pemartín: En torno a la obra de Eduardo Nicol. México, UNAM, 1999; Ricardo Horneffer: Eduardo Nicol. Colegio de Jalisco-Generalitat de Catalunya, 2000; el libro en prensa de Arturo Aguirre Las ideas y los dias.

2 Cf. Armando Savignano: «El problema de la filosofía española», en Anthropos. Extra 3 (1998), pp. 158-163. En la p. 162 (nota 36) se documenta bibliográficamente dicha polémica.

3 Cf. por ejemplo la primera parte de Pensamiento en lengua española. Pensamiento español («El pensamiento hispano-americano. Notas para una interpretación histórico-filosófica»), en José Gaos: Obras com pletas, vol. VI. México, UNAM, 1990, pp. 31-107.

${ }^{4}$ La vocación humana. Presentación de Enrique Hülsz. México, Lecturas mexicanas, 1997., p. 229.

5 Cf. la primera parte de El problema de la filosofia hispánica.

${ }^{6}$ Cf. por ejemplo la cuarta parte de Crítica de la razón simbólica. México, FCE, 2001; Juliana González: o.c.

7 La idea del hombre. México, FCE, 1998, p. 80.
} 


$\begin{array}{ll}8 \text { El porvenir de la filosofia. México, FCE, 1972, } & 12 \text { El porvenir de la filosofia, p. } 21 . \\ \text { p. } 190 . & 13 \text { Ibid., p. } 124 . \\ 9 \text { La idea del hombre, p. } 78 . & 14 \text { Ibid., p. } 132 . \\ 10 \text { Metafísica de la expresión. México, FCE, 1989, } & 15 \text { Ibid., p. } 86 . \\ \text { p. } 159 . & 16 \text { Ibid., p. } 24 . \\ 11 \text { Ibid., p. } 163 . & 17 \text { Ibid., p. } 38 .\end{array}$

